\title{
Predictive Factors of Complications after Coronary Stent Implantation
}

\author{
Alexandre Schaan de Quadros, Carlos A. M. Gottschall, Rogério Sarmento-Leite, Miguel Gus, \\ Rodrigo Wainstein, André Bussmann \\ Porto Alegre, RS - Brazil
}

\begin{abstract}
Objective - To analyze the predictive factors of complications after implantation of coronary stents in a consecutive cohort study.
\end{abstract}

Methods - Clinical and angiographic characteristics related to the procedure were analyzed, and the incidence of major cardiovascular complications (myocardial infarction, urgent surgery, new angioplasty, death) in the in-hospital phase were recorded. Data were stored in an Access database and analyzed by using the SPSS 6.0 statistical program and a stepwise backwards multiple logistic regression model.

Results - One thousand eighteen (mean age of $61 \pm 11$ years, 29\% females) patients underwent 1,070 stent implantations. The rate of angiographic success was $96.8 \%$, the rate of clinical success was $91 \%$, and the incidence of major cardiovascular complications was $7.9 \%$. The variables independently associated with major cardiovascular complications, with their respective odds ratio $(O R)$ were: rescue stent, $O R=5.1$ (2.7-9.6); filamentary stent, $O R=4.5$ (2.2-9.1); first-generation tubular stent, $O R=2.4(1.2-4.6)$; multiple stents, $O R=3$ (1.6-5.6); complexity of the lesion, $O R=2.4(1.1-5.1) ;$ thrombus, $O R=2(1.1-3.5)$.

Conclusion - The results stress the importance of angiographic variables and techniques in the risk of complications and draw attention to the influence of the stent's design on the result of the procedure.

Keywords: interventional cardiology, stents, predictive value, complications

Instituto de Cardiologia do Rio Grande do Sul/Fundação Universitária de Cardiologia.

Mailing address: Alexandre S. Quadros - Unidade de Pesquisa do IC/FUC - Av. Princesa Isabel, 395 - 90620-001 - Porto Alegre, RS, Brazil

E-mail: pesquisa@cardnet.tche.br

English version by Stela Maris C. e Gandour
Percutaneous coronary interventions are currently the main technique for myocardial revascularization, and stents have been used in more than $70 \%$ of these procedures, reducing restenosis and in-hospital mortality ${ }^{1-3}$. Based on the last studies on coated stents and the perspective that restenosis should be drastically reduced ${ }^{4}$, the occurrence or not of complications and the clinical success of the procedure should become the major limitation of this technique. Although many randomized clinical assays have suggested the almost nonexistence of complications, data illustrating the so-called "real world" of clinical practice are not so encouraging. In the recently published dynamic NHLBI registry, the incidence of acute myocardial infarction remained around $3 \%$, of urgent surgery around $1.5 \%$, of death around $2 \%$, and overall success of the procedure around $92 \%{ }^{1}$.

However, few studies have analyzed the predictive factors of complications after percutaneous procedures using only stents ${ }^{5-12}$. Predictive models of complications based on angioplasty studies may overestimate events when applied to a series of patients treated only with stents ${ }^{5}$. Variations in the populations studied and in the criteria of the definition of success and complications reduce the external validity of the studies available ${ }^{13,14}$. Aiming at analyzing predictive factors of complications in patients undergoing stent implantation, we carried out a consecutive cohort study with 1,018 patients undergoing 1,070 stent implantations at a referral hospital for interventional cardiology.

\section{Methods}

In the period from April 1996 to December 2000, 1,092 coronary stents were implanted in 1,030 patients. The patients were prospectively included in an Access database, and clinical and angiographic characteristics were analyzed, as were aspects related to stent implantation and inhospital evolution. The incidence of major and minor cardiovascular complications related to the procedure was recorded, and the patients with intrastent restenosis, in 
cardiogenic shock, or not being clinically followed up were excluded. The sample analyzed comprised 1,070 stent implantations in 1,018 patients, of whom 46 received 2 stents and 3 received 3 stents.

The procedure of stent implantation was performed according to the recommendations in the literature ${ }^{15,16}$. The use of high pressures, type and number of the stents used, coronary angioplasty in another vessel, use of other devices and of glycoprotein IIb/IIIa inhibitors were decided by the surgeons. Most patients were treated with platelet inhibition with acetylsalicylic acid and thienopyridines; in emergency cases, drugs were administered during or right after the procedure.

The following clinical findings were observed prior to the procedure: stable angina, defined as stability of the pattern of pain triggered in the last 2 months; unstable angina, defined as worsening of the intensity or frequency of the anginal pattern in the last 2 months prior to the procedure; angina of recent onset, defined as the presence of angina at rest or thoracic pain with enzymatic alterations with no elevation in the ST segment; acute myocardial infarction, in which case, the procedure was indicated when the patient was referred for mechanical recanalization of the artery related to the infarction in the presence of thoracic pain and elevation in the ST segment.

A successful procedure was defined as stent implantation in the most severe stenosis on angiography with a residual lesion $<30 \%$ and with no major cardiovascular complications. The following events were considered major cardiovascular complications: death, emergency myocardial revascularization surgery, acute myocardial infarction, and new angioplasty. Acute myocardial infarction as a complication of the procedure was defined as the appearance of new $\mathrm{Q}$ waves with elevation in the ST segment or a 5-fold increase in the CPK-MB levels, or both. Myocardial revascularization surgery was defined as the need for urgent revascularization in patients with severe and refractory ischemia during the procedure. The deaths considered were those occurring at the hospital. New angioplasty was defined as the need for new percutaneous revascularization in the vessel treated in the in-hospital phase or in the first month after the index intervention, due to subacute thrombosis of the stent.

Uncomplicated dissections were defined as the appearance of a defect of linear filling $<10 \mathrm{~mm}$ right after stent implantation with or without contrast medium retention, but with no significant impairment in coronary flow (maintenance of TIMI 2 or 3 flow). Loss of branches was defined as the occlusion of branches larger than or equal to $2.0 \mathrm{~mm}$ during or right after the procedure and the occurrence of vascular complications, such as the appearance of a hematoma $\geq 5 \mathrm{~cm}$ in the puncture site, the need for surgical exploration, or the appearance of a pseudoaneurysm.

Evaluations were performed with off-line quantitative angiography or measurements with manual pachymeters. The flow prior to and after the procedure was classified according to the TIMI classification ${ }^{17}$, and the type of stenosis was classified according to the American College of Cardiology modified criteria ${ }^{18}$. A thrombus was defined as an intraluminal filling defect, an eccentric lesion when the stenosis was located in the middle of the supposed normal lumen in at least 1 projection. Vessel occlusion was defined as the appearance of total or subtotal stenosis within or in the margins of the stent with TIMI 0 or 1 flow. The use of high pressures was considered when the postdilatation of the prosthesis was performed with pressure $\geq 14$ ATM.

In regard to indication for stent implantation, it was considered elective when stent implantation was indicated before the procedure, suboptimal when patients were referred with nonocclusive dissections, residual lesions, or elastic removal, and rescue stent implantation when performed during an acute occlusion. The following stents were used: Tenax (Biotronik, Berlin, Germany), 271 implantations; Multilink (Guidant/Advanced Cardiovascular Systems, Santa Clara, California, USA), 260 implantations; Freedom (Global Therapeutics Inc, Cook Company, Broomfield CO, USA), 143 implantations; Vflex (Cook Group Inc, Broomfield, CO, USA), 105; NIR (Medinol Ltd., TelAviv, Israel), 77 implantations; AVE GFX (Arterial Vascular Engineering, Inc., Santa Rosa, California, USA), 73 implantations; BX Velocity (Cordis/Johnson \& Johnson Interventional, Warren, New Jersey, USA), 60 implantations; Iris (Uni-Cath Inc, Saddle Brook, NJ, USA), 44 implantations; Jostent (Jomed AB, Helsinborg, Sweden), 11 implantations; Palmaz Schatz (Cordis/Johnson \& Johnson Interventional, Warren, New Jersey, USA), 9 implantations; Angiostent (Angio Dynamics, Glens Falls, NY, USA), 8 implantations; Tensum (Biotronik GmbH, Berlin, Germany), 5 implantations; Wallstent (Schneider Europe, Lausanne, Switzerland), 1 implantation. In regard to the type of stent implanted, the sample was divided into 4 groups: filamentary (Freedom, angiostent), first generation (Palmaz Schatz, Vflex, Iris, Jostent, Walstent, NIR, GFX), second generation (Multilink, BX Velocity), and coated with silicone carbonite (Tenax, Tensum). Aiming at assessing the influence of the institutional learning curve on the results, the sample was divided into quartiles and analyzed comparatively in relation to the presence of complications.

Categorical variables were presented as percentages, and the continuous variables were presented as mean \pm standard deviation. The differences between the groups of categorical variables were analyzed with the chi-square test, and the differences between the groups of continuous variables were analyzed with the $t$ test for independent samples. Significance levels $<0.05$ were considered statistically significant.

The variables related to clinical, angiographical, and procedural characteristics in the groups with and without complications were compared. The statistically significant variables were selected for inclusion in the stepwise backwards multiple logistic regression model. The following 8 variables were included in the model ${ }^{19}: 1$ ) clinical presenta- 
tion, defined as presence or absence of acute myocardial infarction; 2) length of the lesion, in millimeters; 3) type of lesion, defined as a complex (B2/C) or simple (A/B1) lesion; 4) presence or absence of a thrombus; 5) indication of the procedure, defined as rescue stent or not; 6) type of stent: filamentary, first-generation tubular, last-generation tubular, or stent coated with silicone carbonite; 7) residual stenosis, presented as percentages; 8) use of a single stent or multiple stents. The statistically significant variables are shown with their odds ratio, respective confidence interval, Wald statistics, B coefficient, and significance level.

\section{Results}

The patients' mean age was $60( \pm 11)$ years, and $29 \%$ of them were females. Data referring to the presence of risk factors, previous acute myocardial infarction, previous percutaneous revascularization procedures, ventricular function, extension of arterial impairment, and clinical presentation are shown in table I. Data referring to the angiographic characteristics, type of lesion treated, and characteristics of the lesion are shown in table II. Data referring to the procedure are shown in table III.

The rate of success and major and minor cardiovascular complications are shown in table IV. The index of angiographic success was $96.8 \%$, and the index of clinical success was $91 \%$. Angiographic failure occurred in $3.2 \%$ of the cases (34 patients), and it was mainly due to residual stenoses greater than $30 \%$ ( $2.2 \%$ of the cases, 24 patients); impossibility of crossing the lesion, mal positioning, and loss of the prosthesis were less frequent ( $1 \%$ of the cases, 10 patients). The most frequent major cardiovascular compli- cation was the need for a new angioplasty $(4.8 \%$ of the cases, 52 patients), mainly due to acute occlusion (34 patients) or subacute thrombosis (11 patients). Acute myocardial infarction occurred in 17 patients ( $1.6 \%$ of the cases), urgent surgery in 6 patients $(0.6 \%$ of the cases), and death in 9 patients ( $0.8 \%$ of the cases).

Comparison between the 2 groups in regard to their clinical characteristics is shown in table I. A statistically

\begin{tabular}{|c|c|c|c|c|}
\hline \multicolumn{5}{|c|}{ Table I - Clinical characteristics of patients } \\
\hline & $\begin{array}{c}\text { All } \\
\text { patients }\end{array}$ & $\begin{array}{c}\text { With } \\
\text { MCVC }\end{array}$ & $\begin{array}{c}\text { No } \\
\text { MCVC }\end{array}$ & $\mathrm{P}$ \\
\hline Number of procedures & 1070 & 84 & 986 & \\
\hline Age (years) & $60 \pm 11$ & $60 \pm 11$ & $60 \pm 11$ & NS \\
\hline Female sex (\%) & 29.3 & 34.5 & 28.8 & NS \\
\hline Arterial hypertension (\%) & 41.6 & 36.9 & 42 & NS \\
\hline Smoking $(\%)$ & 26.1 & 22.6 & 26.4 & NS \\
\hline Familial history (\%) & 21.1 & 16.7 & 21.5 & NS \\
\hline Dyslipidemia (\%) & 24.7 & 16.7 & 25.4 & NS \\
\hline Diabetes mellitus (\%) & 26.3 & 32 & 25.8 & NS \\
\hline Previous MRS (\%) & 10.9 & 7.2 & 11.2 & NS \\
\hline $\begin{array}{l}\text { Previous percutaneous } \\
\text { revascularization }(\%)\end{array}$ & 13.1 & 16.7 & 12.8 & NS \\
\hline Previous AMI (\%) & 15 & 8.3 & 15.5 & NS \\
\hline Ejection fraction (\%) & $65 \pm 10$ & $65 \pm 10$ & $65 \pm 9$ & NS \\
\hline $\begin{array}{l}\text { Number of vessels } \\
\text { impaired (\%) }\end{array}$ & & & & NS \\
\hline One & 51.2 & 50 & 51.3 & \\
\hline Two & 35.3 & 40.5 & 34.9 & \\
\hline Three & 13.5 & 9.5 & 13.8 & \\
\hline Clinical presentation (\%) & & & & 0.003 \\
\hline Stable angina & 24.7 & 26.2 & 24.6 & \\
\hline Unstable angina & 64.4 & 51.2 & 65.5 & \\
\hline AMI & 10.9 & 22.6 & 9.9 & \\
\hline
\end{tabular}

\begin{tabular}{|c|c|c|c|c|}
\hline \multicolumn{5}{|c|}{ Table II - Angiographic characteristics } \\
\hline & All patients & With MCVC & No MCVC & $\mathrm{P}$ \\
\hline Number of procedures & 1070 & 84 & 986 & \\
\hline Artery treated $(\%)$ & & & & NS \\
\hline Trunk & 0.8 & 0 & 0.9 & \\
\hline Anterior descending & 53.1 & 54.7 & 53.2 & \\
\hline Circumflex & 13.4 & 12.2 & 13.8 & \\
\hline Right & 28.6 & 28.5 & 28.8 & \\
\hline Saphenous bypass & 5.2 & 6 & 5.2 & \\
\hline Diameter of reference $(\mathrm{mm})$ & $3.36 \pm 0.42$ & $3.21 \pm 0.47$ & $3.38 \pm 0.42$ & $<0.01$ \\
\hline Severity of the stenosis $(\%)$ & $83.4 \pm 10.7$ & $86.7 \pm 11.5$ & $84.4 \pm 11.2$ & $<0.01$ \\
\hline Minimum luminal diameter (mm) & $0.54 \pm 0.37$ & $0.42 \pm 0.35$ & $0.55 \pm 0.38$ & $<0.01$ \\
\hline Length of the lesion (mm) & $9.83 \pm 4.78$ & $11.7 \pm 5.96$ & $10 \pm 5.08$ & $<0.01$ \\
\hline Pre-stent normal flow (TIMI 3) (\%) & 80.8 & 62.7 & 81.5 & $<0.0001$ \\
\hline Type of lesion (ACC classification) \% & & & & $<0.0001$ \\
\hline A & 6.3 & 2.4 & 6.6 & \\
\hline B1 & 20.6 & 8.5 & 21.6 & \\
\hline B2 & 48.6 & 42.7 & 49.1 & \\
\hline $\mathrm{C}$ & 24.5 & 46.3 & 22.6 & \\
\hline Thrombus (\%) & 18.6 & 36.6 & 17.1 & $<0.0001$ \\
\hline Calcium (\%) & 13.4 & 15.9 & 13.2 & NS \\
\hline Ulceration (\%) & 24.4 & 29.3 & 24 & NS \\
\hline Branches $(\%)$ & 35.5 & 34.1 & 35.6 & NS \\
\hline Eccentricity (\%) & 86.7 & 89 & 86.6 & NS \\
\hline
\end{tabular}




\begin{tabular}{|c|c|c|c|c|}
\hline \multicolumn{5}{|c|}{ Table III - Characteristics of the procedure } \\
\hline & All patients & With MCVC & No MCVC & $\mathrm{P}$ \\
\hline Number of procedures & 1070 & 84 & 986 & \\
\hline Indication (\%) & & & & $<0.0001$ \\
\hline Elective & 58.2 & 36.9 & 60.1 & \\
\hline Provisional & 34.6 & 36.9 & 34.5 & \\
\hline Rescue & 7.1 & 26.2 & 5.5 & \\
\hline Type of stent (\%) & & & & 0.006 \\
\hline Filamentary & 14.1 & 25 & 13.2 & \\
\hline First-generation tubular & 22.9 & 29.8 & 22.3 & \\
\hline Last-generation tubular & 36.8 & 26.2 & 37.7 & \\
\hline Silicone carbonite & 25.8 & 19 & 26.4 & \\
\hline Ostial lesion (\%) & 2.1 & 2.4 & 2 & NS \\
\hline Length of the stent (mm) & $16.5 \pm 4.81$ & $18 \pm 5.64$ & $16.5 \pm 4.82$ & $<0.05$ \\
\hline Pressure used (ATM) & $13.1 \pm 2.81$ & $13.1 \pm 3.22$ & $13.1 \pm 2.77$ & NS \\
\hline Diameter of the balloon (mm) & $3.37 \pm 0.37$ & $3.24 \pm 0.41$ & $3.38 \pm 0.37$ & $<0.05$ \\
\hline Residual stenosis (\%) & $1.8 \pm 15$ & $19 \pm 35$ & $0.4 \pm 11$ & $<0.0001$ \\
\hline Final luminal diameter $(\mathrm{mm})$ & $3.3 \pm 0.53$ & $2.7 \pm 1.1$ & $3.3 \pm 0.4$ & $<0.0001$ \\
\hline Glycoprotein inhibitor (\%) & 3.2 & 4.2 & 3.1 & NS \\
\hline Multiple stents (\%) & 10.1 & 23.2 & 8.9 & $<0.0001$ \\
\hline Learning curve (\%) & & & & NS \\
\hline 1st quartile & & 37.2 & 24.2 & \\
\hline 2nd quartile & & 21.7 & 26.6 & \\
\hline 3rd quartile & & 23.5 & 27.9 & \\
\hline 4th quartile & & 19.3 & 23.4 & \\
\hline Angioplasty associated (\%) & 10.3 & 15.5 & 9.8 & NS \\
\hline
\end{tabular}

significant difference in regard to the clinical presentation of the patients was observed, mainly due to a greater number of patients treated for acute myocardial infarction in the group with major cardiovascular complications. The other variables analyzed showed no statistically significant difference between the 2 groups.

Comparison between the 2 groups in regard to the angiographic characteristics is shown in table II. The following findings were associated with the presence of major cardiovascular complications: smaller vessels, more severe stenoses, smaller luminal diameters, longer lesions, and more impaired arterial flow before the implantation. The group with major cardiovascular complications also had a significantly greater number of type $\mathrm{Clesions}$ and angiographically evident thrombi than the group of patients with no complications.

\begin{tabular}{|lr|}
\hline \multicolumn{2}{|c|}{ Table IV - Results of the procedure } \\
\hline Failure & $34(3.2 \%)$ \\
Did not cross the lesion & $2(0.2 \%)$ \\
Mal positioning & $5(0.5 \%)$ \\
Loss of the prosthesis & $3(0.3 \%)$ \\
Residual stenosis $>30 \%$ & $24(2.2 \%)$ \\
Major complications & $84(7.9 \%)$ \\
New angioplasty in the first month & $52(4.8 \%)$ \\
AMI & $17(1.6 \%)$ \\
Urgent surgery & $6(0.6 \%)$ \\
Death & $9(0.8 \%)$ \\
Minor complications & $77(7.2 \%)$ \\
Dissections & $47(4.4 \%)$ \\
Vascular complications & $8(0.7 \%)$ \\
Loss of the branch & $22(2.1 \%)$ \\
Angiographic success & $96.8 \%$ \\
Clinical success & $91 \%$ \\
\hline
\end{tabular}

Data in table III show that the group with major cardiovascular complications had a significantly greater number of patients with acute occlusions after coronary angioplasty prior to stent implantation, while, in the group with no complications, the patients referred for elective stent implantation prevailed. In regard to the type of stent, the patients with complications were more frequently treated with filamentary or first-generation tubular stents, while those with no complications received more lastgeneration tubular stents or those coated with silicone carbonite. The group with major cardiovascular complications received longer stents, smaller balloons, remained with greater residual stenoses and smaller final luminal diameter, and, in addition, in that group, the use of multiple stents was also more frequent.

The stepwise backwards multiple logistic regression model was used in univariate analysis with the following 8 statistically significant variables: acute myocardial infarction, length of the lesion, complexity of the lesion, presence of a thrombus, rescue stent, type of stent, residual stenosis, and use of multiple stents (tab. V). The variables most strongly associated with major cardiovascular complications were the implantation of a rescue stent and the type of stent used (filamentary or first-generation tubular stent). Implantation of multiple stents in the same procedure, complexity of the lesion, and the presence of a thrombus were also statistically significant. The degree of residual stenosis, stent implantation in the presence of acute myocardial infarction, and the length of the stent were not independently associated with major cardiovascular complications, although they were statistically significant in the univariate analysis. 


\begin{tabular}{|lccccc|}
\hline \multicolumn{5}{|c|}{ Table V - Multivariate analysis of the variables related to } \\
complications \\
\hline & $\begin{array}{c}\text { Odds } \\
\text { ratio }\end{array}$ & $\begin{array}{c}\text { Confidence } \\
\text { interval }\end{array}$ & Wald & P & B \\
& & & & & \\
\hline Type of stent & & & & & \\
Silicone carbonite & 1.2 & $0.6-2.3$ & 0.3 & 0.6 & 0.2 \\
1st-generation tubular & 2.4 & $1.2-4.6$ & 6.8 & 0.009 & 1.9 \\
Filamentary & 4.5 & $2.2-9.1$ & 17.8 & $<0.0001$ & 1.5 \\
Complex lesion & 2.4 & $1.1-5.1$ & 5.3 & 0.02 & 0.9 \\
Rescue stent & 5.1 & $2.7-9.6$ & 25 & $<0.0001$ & 1.6 \\
Multiple stents & 3 & $1.6-5.6$ & 12 & 0.005 & 1.1 \\
Thrombus & 2 & $1.1-3.5$ & 5.4 & 0.02 & 0.7 \\
Constant & & & 103.4 & $<0.0001$ & 4.3 \\
\hline
\end{tabular}

\section{Discussion}

The patients studied comprised a representative sample of a tertiary referral center exclusively dedicated to patients with cardiac diseases. These data may help in assessing the risk of complications in patients undergoing stent implantation in conditions similar to those reported. In this study analyzing 1,070 implantations of coronary endoprostheses in 1,018 consecutive patients, the major predictors of cardiovascular complications were the type of stent used (filamentary or first generation), implantation of rescue stents, complexity of the lesion, presence of a thrombus, and use of multiple stents in the same procedure.

The type of stent implanted, the major finding in this study, was one of the major variables independently associated with major cardiovascular complications, a result that had not been previously reported in studies specifically designed for the analysis of complications ${ }^{5,6,11,20}$. Holmes et al ${ }^{5}$, analyzing 3,761 patients undergoing stent implantation, observed that the New York State model of risk prediction was the major predictive factor of complications; however, the types of stents used were not reported ${ }^{5}$. Schünlen et al ${ }^{11}$ studied 2,444 patients and identified several clinical and angiographic characteristics (mainly residual dissections and the lack of the use of ticlopidine) associated with complications, but not with the type of stent. Likewise, in the studies by Moscucci et al ${ }^{6}$ and Kastrati et al ${ }^{20}$, the type of stent was also not associated with complications. On the other hand, results from some observational studies have shown up to 2 -fold variations in the incidence of complications with the use of different types of stents ${ }^{21}$. Our data showed a 4.5-fold risk of complication (CI: 2.2-9.1) greater with filamentary stents, and a 2.4-fold risk of complication (CI: 1.2-4.6) greater with first-generation tubular stents. These findings are in accordance with those of previous studies showing a weaker radial strength of filamentary stents and the possibility of a greater prolapse of the plate between their rods, allowing greater residual stenoses and a greater thrombogenic substrate ${ }^{22}$. Although these models of prostheses are no longer being used clinically, these results emphasize the importance of the design and shape of the stent in the outcome of the procedure and may be important in the future, when the availability of stent coating with antiproliferating drugs may lead to greater flexibility in the models and designs of the prostheses.

The use of stents to rescue acute occlusions of angioplasty was the variable associated with a greater risk of major cardiovascular complications, with an odds ratio of $5.1(\mathrm{CI}$ : 2.7-9.6) compatible with data reported in the literature ${ }^{23,24}$. The use of multiple stents was also associated with a greater risk, probably due to the larger metallic surface, and also to their overlapping ${ }^{10,11}$.

The complexity of the lesion has traditionally been one of the factors most frequently associated with major cardiovascular complications in most studies analyzing predictive factors of complications after coronary angioplasty ${ }^{6,9,20}$; however, its importance has been questioned when the procedure involves stent placement ${ }^{12}$. The complexity of the lesion was one of the variables independently associated with complications in the studies by Moscucci et $\mathrm{al}^{6}$ and by Holmes et a ${ }^{5}$, but not in the study by Schünlen et $\mathrm{al}^{11}$. In our study, the patients with complex lesions had a 2.4-times greater risk of complications (CI: 1.1-5.1).

Although the procedure performed in the presence of acute myocardial infarction was statistically significant in the univariate analysis, it was not independently associated with the occurrence of major cardiovascular complications, contrary to findings in most previous studies ${ }^{6,7,9,11}$. The reasons for this finding are not clear, although the concomitance of patients with acute myocardial infarction, thrombus, and rescue conditions may have influenced the model. Residual stenosis and length of the lesion, although significant in univariate analysis, were not significant in the final model. Likewise, age and left ventricular dysfunction were not also associated with complications, even in a univariate analysis.

The index of clinical success in this study is comparable to those in several previous studies, considering the differences in the criteria of success and major cardiovascular complications used (in our study, the need for a new percutaneous intervention in the in-hospital phase or in the first month due to subacute thrombosis was considered a major complication) $1,5,11,25,26$. Some randomized clinical assays have reported rates of success of up to $99 \%$, but in groups of patients at very low risk, excluding ongoing acute myocardial infarction and patients with unfavorable angiographic criteria ${ }^{21}$.

Major cardiovascular complications occurred in $7.9 \%$ of our patients, with the incidence of acute myocardial infarction, urgent surgery, and death similar to those reported in the literature. The high incidence of acute occlusions (3.1\% of the patients) may be attributed to the high frequency of acute occlusions in coronary angioplasty and the large number of patients with ongoing acute myocardial infarction. Seventy-one patients ( $7.1 \%$ of the total) (tab. III) were treated for acute occlusions during angioplasty, and, in that subgroup, the possibility of a patient remaining in acute occlusion was 7 times greater than the risk of an elective patient presenting with that problem, a finding compatible with data reported in the literature ${ }^{11,20}$. 
This study was initiated in 1996, including filamentary and first-generation stents. The evolution of the techniques of implantation and the most frequent use of glycoprotein IIb/IIIa inhibitors may have limited the extrapolation of the results. Although the patients were prospectively included, the data analysis was retrospective, which could also introduce bias in assessing the study. Although the clinical characteristics played no significant role as determinants of in-hospital complications, they are well-known important predictors of a long-term prognosis.

In conclusion, the major finding of this study was that the type of stent, filamentary or first generation, contributes as one of the factors most strongly associated with the occurrence of major cardiovascular complications after implantation. Other variables statistically associated with major cardiovascular complications in the multiple logistic regression model were rescue stents, use of multiple stents, complexity of the lesion, and the presence of a thrombus prior to implantation. These results emphasize the importance of angiographic variables and techniques in the risk of complications and draw attention to the influence of the stent's design on the result of the procedure.

\section{Acknowledgments}

We thank Mrs. Vânia Hirakata for the statistical analysis.

\section{References}

1. Wiliams DO, Holubkov R, Yeh W, et al. Percutaneous coronary intervention in the current era compared with 1985-1986. The National Heart, Lung, and Blood Institute Registries. Circulation 2000;102; 2945-51.

2. Rankin JM, Spinelli JJ, Carere RG, et al. Improved clinical outcome after widespread use of coronary-artery stenting in Canada. N Engl J Med 1999; 341: 1957-65.

3. Kimmel SE, Localio AR, Krone RJ, et al. The effects of contemporary use of coronary Stents on in-hospital mortality. Registry Committee of the Society for Cardiac Angiography and Interventions. J Am Coll Cardiol 2001; 37: 499-504.

4. Souza JE, Costa MA, Abizaid A, et al. Sustained supression of neointimal proliferation by sirolimus-eluting Stents: one-year angiographic and intravascular ultrasound follow-up. Circulation 2001; 104: 2007-11.

5. Holmes DR, Berger PB, Garratt KN, et al. Application of the New York State PTCA mortality model in patients undergoing stent implantation. Circulation 2000; 102: 517-22.

6. Moscucci M, Kline-Rogers E, Share D, et al. Simple bedside additive tool for prediction of in-hospital mortality after percutaneous coronary interventions. Circulation 2001; 104: 262-8.

7. O'Connor GT, Malenka DJ, Quinton H, et al., for the Northern New England Cardiovascular Disease Study Group. Multivariate prediction of in-hospital mortality after percutaneous coronary interventions in 1994-1996. J Am Coll Cardiol 1999; 34: 681-91.

8. Ellis SG, Weintraub W, Holmes D, Shaw R, Block PC, King $3^{\text {rd }}$ SB. Relation of operator volume and experience to procedural outcome of percutaneous coronary revascularization at hospitals with high interventional volumes. Circulation 1997; 96: 2479-84.

9. Moscucci M, O'Connor GT, Ellis SG, et al. Validation of risk adjustment models for in-hospital percutaneous transluminal coronary angioplasty mortality on an independent data set. J Am Coll Cardiol 1999; 34: 692-7.

10. Ellis SG, Buetta B, Miller D, Whitlow PL, Topol EJ. Relation between lesion characteristics and risk with percutaneous intervention in the stent and glycoprotein Iib/IIIa era: an analysis of results from 10907 lesions and proposal for new classification scheme. Circulation 1999; 100: 1971-6.

11. Schünlen H, Kastrati A, Dirschinger J, et al. Intracoronary stenting and risk for major adverse cardiac events during the first month. Circulation 1998; 98: 104-11.

12. Maier W, Mini O, Antoni J, Wischnewsky MB, Meier B. ABC stenosis morphology classification and outcome of coronary angioplasty. Circulation 2001; 103: $1225-31$.

13. Lindsay J, Pinnow EE, Popma JJ, Pichard AD. Obstacles to outcomes analysis in percutaneous transluminal coronary revascularization. Am J Cardiol 1995; 76: 168-72.
14. Block PC, Peterson EC, Krone R, et al. Identification of variables needed to risk adjust outcomes of coronary interventions: evidence-based guidelines for efficient data collection. J Am Coll Cardiol 1998; 32: 275-82.

15. Holmes DR, Hirshfield J, Faxon D, et al. ACC Expert Consensus Document on Coronary Artery Stents. Document of the American College of Cardiology. J Am Coll Cardiol 1998; 32: 1471-82.

16. Carrozza JP, Baim DS. Coronary stenting. In: Baim DS, Grossman W, eds. Grossman's Cardiac Catheterization, Angiography, and Intervention. $6^{\mathrm{a}}$ ed. Philadelphia, EUA: Lippincott Wiliams \& Wilkins, 2000: 637-66.

17. The TIMI Study Group. The Thrombolysis in myocardial infarction (TIMI) trial: Phase I findings. N Engl J Med 1985; 312: 932-6.

18. Baim DS. Coronary angioplasty. In: Baim DS, Grossman W, eds. Grossman's Cardiac Catheterization, Angiography, and Intervention. $6^{\text {a }}$ ed. Philadelphia, EUA: Lippincott Wiliams \& Wilkins, 2000: 547-600.

19. Concato J, Feinstein AR, Holford TR. The risk of determining risk with multivariable models. Ann Intern Med 1993; 118: 201-10.

20. Kastrati A, Schömig A, Elezi S, et al. Prognostic value of the modified American College of Cardiology/American Heart Association stenosis morphology classification for long-term angiographic and clinical outcome after coronary stent placement. Circulation 1999; 100: 1285-90.

21. Kastrati A, Dirschinger J, Boekstegers P, et al. Influence of stent design on 1-year outcome after coronary stent placement: a randomized comparison of five stent types in 1147 unselected patients. Catheter Cardiovasc Interv 2000; 50: 290-7.

22. Lansky A, Roubin G, O'Shaughnessy CD, et al. Randomized comparison of GRII stent and Palmaz-Schatz stent for elective treatment of coronary stenoses. Circulation 2000; 102: 1364-8.

23. Schömig A, Kastrati A, Mudra H, et al. Four-year experience with Palmaz-Schatz stenting in coronary angioplasty complicated by dissection with threatened or present vessel closure. Circulation 1994; 90: 2716-24.

24. Sutton JM, Ellis SG, Roubin GS, et al. Major clinical events after coronary stenting. The multicenter registry of acute and elective Gianturco-Roubin stent placement. The Gianturco- Roubin Intracoronary Stent Investigator Group. Circulation 1994; 89: 1126-37.

25. Mattos LA, Pinto I, Abizaid A, et al. Safety and efficacy of coronary stent implantation. Acute and six month outcomes of 1126 consecutive patients treated in 1996 and 1997. Arq Bras Cardiol 1999; 73: 30-6.

26. Kastrati A, Schömig A, Dirschinger J, et al. Increased risk of restenosis after placement of gold-coated stents: results of a randomized trial compring goldcoated with uncoated steel stents in patients with coronary artery disease. Circulation 2000; 101: 2478-83. 